\section{A Pan-American Medical Congress.}

To the Editor:-I beg leave to announce to the members that it is my intention to move at the Washington meeting, I. That the American Medical Association extend to the profession of the Republics and Colonies of the Western Continent an invitation to assemble in this country in an Intemational American Medical Congress; and, if this resolution be adopted, then, 2. That the Nominating Committee be instructed to report a committee of one from each State and territory, and one each from the Army, Navy, and Marine Hospital Service, to whom shall be referred the time, place, and permanent organization of the proposed Congress.

There is substantial reason why this step should be taken and why the proposed Congress should be held. Polite learning has always followed in the wake of commerce. The recently established and rapidly developing politico commercial relations between the United States and the other countries of the two Americas must, in the nature of things, bring about an interchange of the sciences and arts. Among these latter, medicine in its broad sense will be the first to be forced into the foreground. The restrictions which are placed upon commerce in the interest of health make it imperative that problems of naval hygiene and international sanitarian be discussed and definitely settled. The question of epidemics, their causation, propagation and habitat, becomes, as never before, one fraught with imminent commercial and vital importance. Pressing hard upon both these broad and comprehensive themes, indeed forming integral parts of them, is the great and developing department of bacteriology. Through the medium of this newest of medical departments all branches of medicine and surgery have become intimately correlated. Thus we discover at once that, between the United States and the other countries of the Western Continent there exists a commercial interest in all topics which can engage the attention of a Medical Congress.

The medical schools of Latin America are generally endowed and enjoin a curriculum which insures the scholarship of their alumni. The recent graduates, however, go to the European schools for advanced study. If the profession of the Southern Republics could be induced to visit the United States and thus become familiar with the clinical and educational resources of our great cities the result would doubtless be an increased enrollment from these countries in both our underand post-graduate schools. On the other hand our own students desirous of prosecuting their studies in a language which shall have a commercial as well as a classical importance may find it profitable to spend a season among the hospitals and laboratories of Havana, Rio Janeiro and Buenos Ayres.
I beg to state that early last winter I opened a personal correspondence with distinguished medical gentlemen of Mexico, Central America and South America, requesting their individual views as to the exediency of such a Congress and that the replies so far received are uniformly favorable.

My apology for bringing this matter up before the assembling of the Association must be found in the importance of the contemplated action and in the further importance of having the delegates come to the meeting able to reflect in some measure the sentiments of the profession whom they represent.

$$
\text { Chardes A. L. ReEd, M.D. }
$$

Cincinnati, April 6, I8gr.

\section{Phymosis.}

To the Editor:-Page $27 \mathrm{I}$ in No. 8 of THE JOURNAL contains an article on "Painless Circumcision" by Dr. G. W. Overall, with which I was much pleased. It is a great step in advance of the old method of giving chloroform, which several times in my practice endangered the life of the little patient. Since then I have to a certain extent followed the method of Dr. Overall. That is, I have used a 20 or 30 per cent. solution of cocaine and injected to or 15 drops with a blunt pointed glass syringe into the preputial orifice, pressing the prepuce tightiy around the end so as to retain the fluid, after removing the syringe. I churned the fluid cocaine so as to come in contact with the entire mucous membrane for ten or fifteen minutes. I at the same time sprayed over the entire integument where the circumcision was to take place an anæsthetic solution consisting of

R. Chloroform, 3 ijss.

Ether sulphuric, 3 iv.

Menthol, grs, xv. mo.

until I felt satisfied that complete anæsthesia of the part was produced. I now begin the now painless operation and so far I have not been disappointed in that respect. A fine catgut interrupted suture wiil soon unite the edges. Dress with iodoform gauze and bi-chlorinated cotton, and you will have every reason to feel satisfied with the best method of operating for phymosis. Tepid water sprays and dressings will keep down all local inflammation should there be much.

If the operation now required for enuresis of long standing a little medication may be necessary for a week or two after the operation, in that case I have found excellent results from the following:

R. Atropiæ sulph.; gr. ij.

Aquæ distil. 3 j. m.

Sig. One drop for each year of age of the child, at 4 and 7 P.M. Increase the dose if no effect is produced in one week.

All nervous irritation, spasms, convulsions in the little sufferer will generally rapidly subside.

I will close by saying that all male children troubled with enuresis and all other nervous dis- 
eases of a reflex nature should never be prescribed for unless the physician is satisfied from actual observation that no condition of phymosis exists. If there is, circumcision is the only radical cure. Alta, Iowa.

B. STORCH, M.D.

\section{SPECIAL CORRESPONDENCE.}

\section{Shall The Journal be Removed to Washington?}

THE VOICE OF OUR MEMBERS AS SHOWN BY A VOTE OF THE SAME ON THE QUESTION OF THE REMOVAL OF THE JOURNAL FROM CHICAGO TO WASHINGTON.

As straws slow which way the gentle zephyrs blow; Thus Votes, the will of our Association slow !

The agitation on the part of some of the Trustees, which contemplates a removal of THE JoURNAL of the Association from Chicago to Washington, was scarcely announced, before a general feeling of opposition was clearly evident in a large majority of the more active members of the entire Association-North, South, East and West. But how to obtain an expression from the members regarding such a movement, and, at the same time, put in force the will of the majority of the same under all the circumstances, was a perplexing question. The Association being made up of permanent members and delegates, the former having no vote and the latter having become extinct by virtue of their adjourning sine die, there was no official way by which an expression of the will of the members could be obtained prior to the coming meeting. In other words, our Association is like a chrysalis, so far as any official action of its members is concerned between each annual meeting. This being the case it was patent to every one that no official action could be taken on this vital question by the members before the meeting at Washington. Yet this did not prevent any permanent member from canvassing the field and ascertaining as neaily as possible the feelings of the members regarding the proposed removal of THE JOURNAL to Washington. The result was that after several consultations with numerous friends of THE JOURNAL who were simply high privates in the rear ranks of our membership, I decided to conduct a com. plete canvass of the members and ascertain their individual opinions on this most important question. Consequently I prepared and mailed, or had mailed, to each permanent member of the Association, the following circular letter with which I enclosed a postal card addressed to myself, or such others as were assisting me, on which the following blank was printed:

My Dear Doctor:-You are no doubt aware long ere this that an effort is being made to remove The Journal of the American Medical Association from Chicago, Ill., to Washington, D. C. As I am desirous of obtaining a free expression from the leading members of the Association, of their candid opinion in regard to this all important question, I herewith enclose you a blank postal card on which I will ask you to kindly inform me whether you are in favor or opposed to this movement to change the place of publication of our National Journal from the Western Metropolis to the National Capital; to which we will be pleased to have you add the principal reason "for the faith that is within you."

Trusting that I may have the honor to receive an early reply through your courtesy, I remain,

Sincerely and Fraternally Yours,

Mansfield, $O$. R. HARVEY REED.

Dear Doctor:-In answer to your inquiry of . IS9I. I 89I, regarding the removal of "The Journal" of the American Medical Association from Chicago to Washington, it is, in my opinion, to the best interests of the "Jourial" to have it

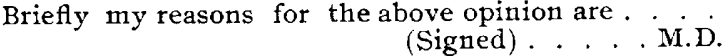

In this work I was ably assisted by Dr. T. D. Crothers, of Hartford, Conn., who sent out the same circular to the members in the Fastern States, and received and recorded their views. Likewise I was assisted by Dr. C. E. Beardsley, of Ottawa, O., who looked after the votes in Ohio, and Dr. John F. Fulton, of St. Paul, Minn., who canvassed Minnesota, and Dr. T. M. Hood of Weston, W. Va., who secured the votes for his State; all of which votes have been carefully recorded on tally sheets prepared for that purpose, of which the following is a fac simile, giving the name, his postoffice address, together with his vote, all of which is backed by his reply on the postal card or letter he returned, which has been carefully filed away for future reference.

TAI,Y SHEET. - Showing the Record of the Returns of the Votes taken, with Reference to the removal of "The Journal" of the American Medical Association from Chicago, Ill., to Washington, D. C.

Returned to Dr. R. Harvey Reed, Mansfield, O., by Dr. of . . . . St. Post Office, State of . Division.

\begin{tabular}{c|c|c|c|c|}
\hline Names. & Post Office. & State. & $\begin{array}{l}\text { Vote for } \\
\text { Chicago for }\end{array}$ & Remarks \\
\hline & &
\end{tabular}

After recording the votes on these tally sheets we journalized them, so to speak, into States, giving the total number of members in each State, to each of whom a circular had been sent; the total number of votes received from each State; the total number for Chicago; the total number for Washington, and the total number for other places, or those who were undecided or had no preference, all of which is clearly shown by the following tabulated report. This report was closed on the 8th of April, notwithstanding we were receiving quite a number of votes daily, and have continued to receive them ever since it 